\title{
Changes in splenic melano-macrophage centres of dab Limanda limanda during and after infection with ulcer disease
}

\author{
Heidemarie Kranz \\ Universität Hamburg, Zoologisches Institut \& Zoologisches Museum, Martin-Luther-King-Platz 3, D-2000 Hamburg 13 , \\ Federal Republic of Germany
}

\begin{abstract}
Splenic melano-macrophage centres (MMC) and associated parenchymic structures were compared in 3 groups of dab Limanda limanda L. from the North Sea: healthy fish, fish with ulcers, and fish with healed ulcers still recognizable as scars on the body surface. Dab with open ulcers showed enlarged splenic MMC somewhat reduced in frequency and with increased haemosiderin content. During this stage of infection the density of pigmented granules within MMC was reduced in favour of homogeneously scattered cells or a centrally located aggregation of cells, all of which lacked phagocytic inclusions. Leucocytes were accumulated to an elevated degree around splenic capillaries. Because of the reduced occurrence of single pigment-bearing cells in the splenic parenchyma and the very regular, rounded shape of the $\mathrm{MMC}$, it is thought that during this stage of the disease the turnover rate in formation and destruction of MMC was diminished. On the other hand, the increase in seemingly nonphagocytic leucocytes in the MMC indicates a possible augmentation of the humoral immune response. After healing of the ulcers all splenic changes accompanying infectious conditions regressed. However, a return to the normal picture seen in healthy fish did not occur as long as scars were still visible in the skin.
\end{abstract}

\section{INTRODUCTION}

Melano-macrophage centres (MMC) in haematopoietic organs of bony fish occur in head kidney, spleen, and, more rarely, in the liver. They are aggregations, mainly of macrophages, in which phagocytosed substances are catabolized, remobilized, or deposited. According to the varying proportions of melanin and lipofuscin contained, their coloration varies between light yellow and nearly black in histological sections. Increased occurrence of melanin in poikilothermic animals is attributed to the catabolism of fatty acids at low temperatures (Edelstein 1971). Lipofuscin is considered to be a catabolic product resulting from the destruction of cellular components, especially biological membranes (Agius \& Agbede 1984). Another pigment that is abundant in MMC, named haemosiderin, derives from the catabolism of erythrocytes.

In addition to phagocytosing foreign particles or effete cells from an organism, MMC are involved in immunological functions. For this reason they have been interpreted as precursors of the germinal centres in the lymph nodes of higher vertebrates (Ellis 1980).

Size, frequency, and pigmentation of MMC have been observed to vary with starvation, disease, pollution, and fish age (Agius 1979, Agius \& Roberts 1981, Weeks \& Warriner 1984, Brown \& George 1985, Wolke et al. 1985, Kranz \& Gercken 1987). Owing to these reactions, $\mathrm{MMC}$ have been discussed as indicators of the health status of fish in biological effect monitoring (Blazer et al. 1987). However, a clear distinction of MMC alterations caused by the different single influences mentioned has not yet been established. If MMC are to be useful as indicators of exposure to noxious agents, changes from the norm induced in the MMC by the agents should disappear once contact with the noxious agents is removed.

MMC vary between the different haematopoietic organs. Splenic MMC are more abundant and larger than those in the liver; compared to kidney, they are more variable in pigmentation and show a closer degree of aggregation (Agius 1979, Kranz \& Peters 1984).

The present investigation examined alterations in splenic MMC of dab Limanda limanda L. from the North Sea: the MMC of healthy individuals were com- 
pared with those of fish suffering from open ulcers and with those of fish that had recovered from the disease but in which scars were still visible on the body surface. Ulcer disease is a widespread infectious condition that has been recorded in 15 fish species from the North Sea (Dethlefsen 1984).

In cod Gadus morhua, which are frequently affected by ulcer disease, viruses have been considered as the primary infectious agent; invariably, however, infections with bacteria of the genus Vibrio follow (Jensen \& Larsen 1982). The disease is characterized, especially in the chronic stage, by large, bloody skin ulcers, which usually extend into the underlying musculature. The borders of the ulcers contain necrotic tissue and macrophaqe aggregations (Roberts 1978).

\section{MATERIALS AND METHODS}

In May 1986, 81 dab were taken from the Dogger Bank area in the southern North Sea. Thirty of them had open ulcers on the body surface, 21 had recovered from ulcerous inflammation, as seen from scars on the skin, and 30 reference fish showed no external or internal sign of disease. To avoid any influence of sexual diversity or gonadal maturation, only female dab between 19 and $26 \mathrm{~cm}$ in length were used (healthy fish: $21.8 \pm 1.44 \mathrm{~cm}$; ulcerous fish: $21.6 \pm 1.85 \mathrm{~cm}$; scarred fish: $22.2 \pm 1.79 \mathrm{~cm}$ ). The dab were killed and dissected, and the spleens were fixed with Bouin's fluid. Organs were processed using routine histological methods to yield sections $3 \mu \mathrm{m}$ in thickness. The following stains were used: haematoxylin and eosin as a general stain; Azan for identification of fibrous tissue elements; and Prussian blue to detect haemosiderin in MMC.

Quantitative changes in the number and size of the splenic MMC were determined by counting and by planimetry. The results were expressed in terms of the frequency of $\mathrm{MMC}$ in a defined splenic area, the average size of $M M C$ per section of organ, and the percentage of organ area occupied by MMC. Frequency and size of splenic MMC in the three study groups were compared using the $U$-statistic of Wilcoxon, Mann and Whitney.

\section{RESULTS}

The spleen of teleosts has generally been considered as storage organ for blood cells, and beyond that it has functions in haematopoiesis, destruction of blood cells, and immunological processes. The basic structure of the spleen is a network of reticular cells (Figs. 1 and 2), in which erythrocytes, leucocytes, pigment cells, and a widely ramified system of blood vessels are embedded.
This reticular stroma forms thicker wall-structures around terminal capillaries, called ellipsoidal sheaths (Fig. 3); the stroma sometimes encapsulates MMC, in which case the MMC appear as uniformly rounded structures (Fig. 4).

The MMC and single macrophages in the parenchyma are recognizable in histological sections because of their cytoplasmic pigments: black-brown melanin, yellow lipofuscin, and haemosiderin.

The splenic MMC of dab contained low amounts of melanin compared with other species (e.g. plaice) and their haemosiderin content and certain other of their features along with those of their associated parenchymal structures differed according to the study group: healthy, ulcerous, or scarred dab (see Tables 1 and 2). The most obvious feature in the spleen of dab with open ulcers on the body surface was an increase in size of the MMC. On average, the MMC were $50 \%$ larger than in normal fish $(p<0.001)$. This corresponded approximately to an overall increase in MMC area per organ section, because the frequency of $\mathrm{MMC}$, although slightly reduced in number, was not significantly altered $(p>0.3)$.

Haemosiderin always occurred only in the macrophages assembled in the MMC (Figs. 5 and 6); single cells scattered in the splenic parenchyma between ellipsoids and $\mathrm{MMC}$ never showed positive reactions with Prussian blue. Haemosiderin in MMC occurred most frequently in the spleens of ulcerous fish (Table 2), although pigmented inclusions or phagosomes displaying very fine granulation were mostly loosely arranged in their MMC. No distinct differences in melanin content of splenic MMC were obvious in the 3 study groups

In dab with open ulcers, the MMC often contained cells lacking cytoplasmic inclusions in addition to the pigment-bearing macrophages. The unpigmented cells contained a large, often round, nucleus with a marginal distribution of chromatin. These cells were either loosely scattered in the MMC or were concentrated in the centre of the MMC such that the phagosome-and/ or pigment-containing macrophages were restricted to

Table 1 Limanda limanda. Size, MMC area as percentage of organ area, and frequency of MMC in spleens of healthy, ulcerous, and scarred dab from the North Sea. Values shown are means \pm standard error

\begin{tabular}{|lrrrr|}
\hline MMC & \multicolumn{1}{c}{ Healthy } & \multicolumn{1}{c}{ Ulcerous } & \multicolumn{1}{c|}{ Scarred } \\
\hline Size $\left(\mathrm{um}^{2}\right)$ & $984.3 \pm 67.2$ & $1422.7 \pm 103.0$ & $1131.5 \pm 83.2$ \\
Area per or & $4.4 \pm 0.5$ & $5.7 \pm$ & 0.5 & $4.9 \pm 0.4$ \\
gan area (\%) & & & & \\
$\begin{array}{l}\text { Frequency } \\
\left(n \mathrm{~mm}^{-2}\right)\end{array}$ & $44.3 \pm 3.9$ & $40.1 \pm$ & 2.4 & $45.2 \pm 3.6$ \\
\hline
\end{tabular}


Table 2. Limanda limanda. Qualitative evaluation of histological characteristics associated with splenic MMC in healthy, ulcerous, and scarred dab from the North Sea. Percentage values refer to numbers of organs examined. Unless otherwise stated, evaluations refer to $H \& E$ staining of tissue sections

\begin{tabular}{|c|c|c|c|}
\hline Histological characteristic & Healthy & Ulcerous & Scarred \\
\hline \multicolumn{4}{|l|}{ Haemosiderin content of $\mathrm{MMC}$} \\
\hline \multicolumn{4}{|l|}{ (Prussian blue staining) } \\
\hline Negative & $33 \%$ & $13^{\circ}$ & $19 \%$ \\
\hline Moderate & $37 \%$ & $60 \%$ & $76 \stackrel{\mathrm{u}}{\mathrm{u}}$ \\
\hline Strong & $29 \%$ & $27 \%$ & $5 \%$ \\
\hline \multicolumn{4}{|l|}{ Arrangement of pigments within $\mathrm{MMC}$} \\
\hline Compact & $50 \%$ & $27 \%$ & $38 \%$ \\
\hline Scattered & $13 \%$ & $23 \%$ & $38 \%$ \\
\hline Marginal & $37 \%$ & $50 \%$ & $24 \%$ \\
\hline \multicolumn{4}{|l|}{ Distinct encapsulation of $\mathrm{MMC}$} \\
\hline (Azan staining) & $56 \%$ & $79 \%$ & $67 \%$ \\
\hline \multicolumn{4}{|l|}{ Connective tissue extending through $\mathrm{MMC}$} \\
\hline (Azan staining) & $11 \%$ & $32 \%$ & $19 \%$ \\
\hline Irregularly notched surface of $\mathrm{MMC}$ & $43 \%$ & $33 \%$ & $48 \%$ \\
\hline \multicolumn{4}{|l|}{ Distinct RES ${ }^{a}$ structures within splenic parenchyma } \\
\hline (Azan staining) & $89 \%$ & $64 \%$ & $71 \%$ \\
\hline Distinct ellipsoid sheaths & $93 \%$ & $86 \%$ & $91 \%$ \\
\hline Aggregations of leucocytes surrounding ellipsoids & $55 \%$ & $68 \%$ & $57 \%$ \\
\hline Single macrophages within splenic parenchymab & $47 \%$ & $17 \%$ & $29 \%$ \\
\hline Single macrophages within blood vessels ${ }^{b}$ & $30 \%$ & $17 \%$ & $29 \%$ \\
\hline
\end{tabular}

the border of the MMC (Fig. 7). In Azan-stained splenic sections from ulcerous fish, reticular cells often occurred, stroma-like, within the MMC and also surrounded them by forming a thin capsule (Table 2). The irregular notched shape of the MMC, seen in normal fish, was seldom seen within diseased fish. Single macrophages, recognizable because of their yellow to brownish inclusions, occurred with reduced frequency within the parenchyma of ulcerous fish (cf. Figs. 5 and 6). The same held true for melanin-containing cells within the splenic blood vessels of these fish (Fig. 8).

In dab with open wounds, the prominent reticular structures observed within and surrounding MMC contrasted with the less well developed reticular stroma within the splenic parenchyma and the ellipsoidal sheaths associated with the blood vessels. In these fish, leucocyte accumulations were abundant around ellipsoids.

All alterations of cellular splenic components noted during the open ulcer phase were clearly less pronounced after healing of the ulcers (Table 2). However, as long as scars were visible on the body surface most of the altered parameters had not yet returned to the values observed in the fish considered healthy. Statistically, the MMC size differed significantly between ulcerous and scarred fish $(p<0.025)$ but not between healthy and scarred fish $(p>0.06)$. The frequency of MMC was never significantly different between any 2 of the 3 studied groups.

\section{DISCUSSION}

In dab with ulcer disease the proportion of the spleen occupied by MMC was increased.

The mechanism of macrophage settlement in the spleen of fish has been revealed by means of injected carbon particles (Ferguson 1976, Lamers \& Parmentier 1985). The carbon first appeared in the ellipsoidal sheaths and then, ingested by single macrophages presumably deriving from the reticular cells surrounding the blood vessels, migrated through the parenchyma and finally settled within existing or newly formed MMC.

The increase of splenic MMC tissue during ulcerous infection of dab was due to an increase in area of the MMC rather than an increase in their frequency. This means that newly settled splenic macrophages aggregated with already existing MMC. The almost negligible reduction in frequency of $\mathrm{MMC}$ during disease may have been due to a fusion of some MMC.

Earlier investigations have shown that MMC both in 

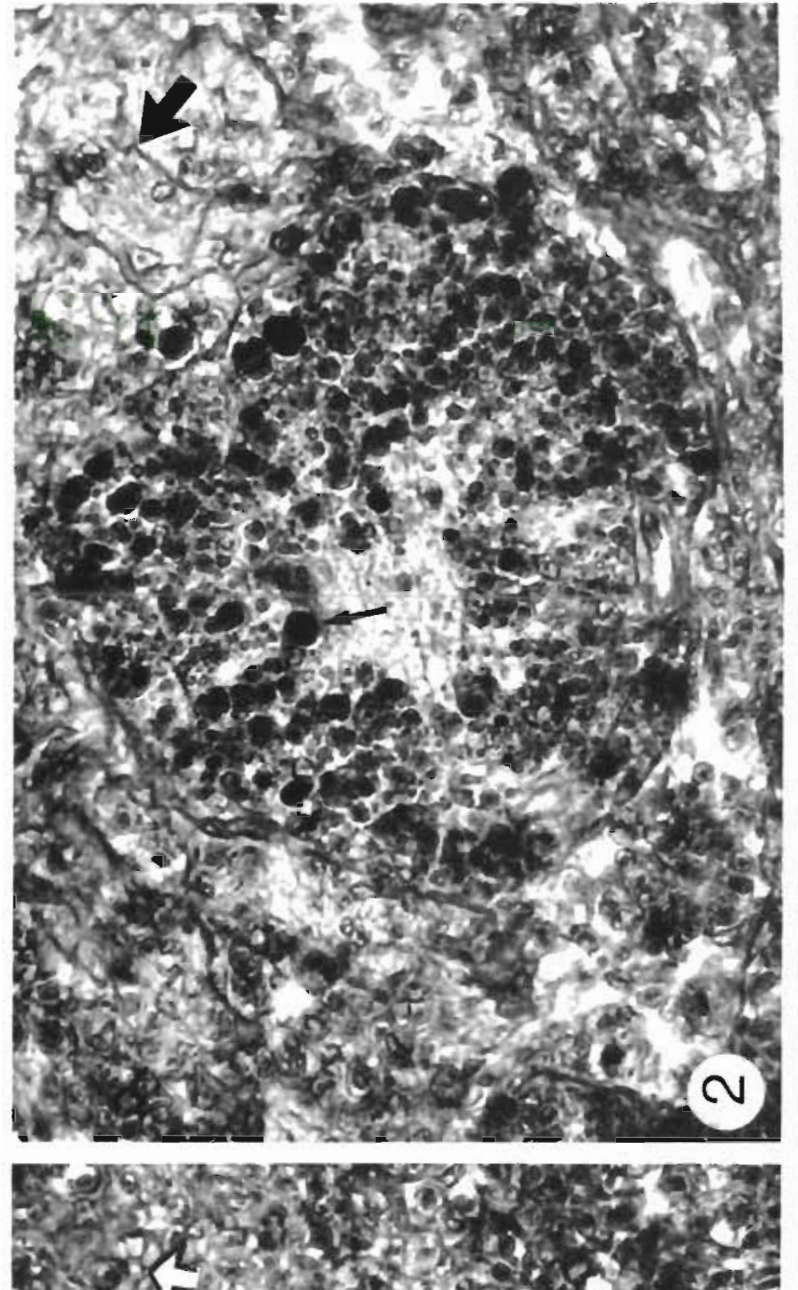

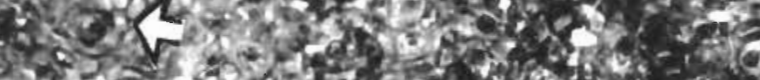

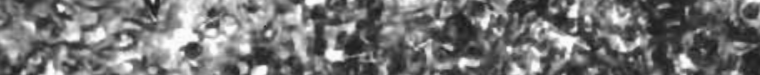

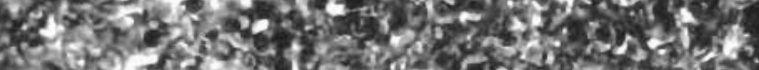

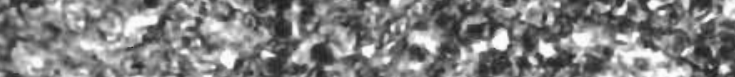

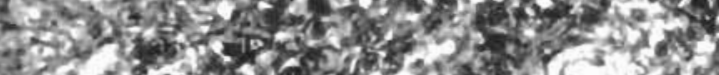

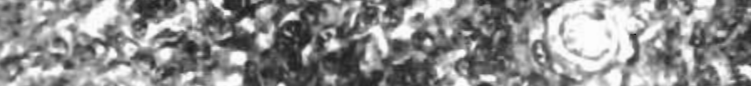

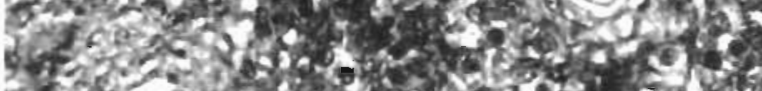

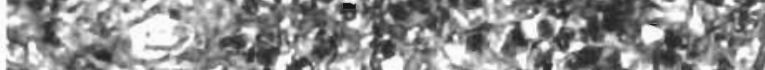
(2) 5 a

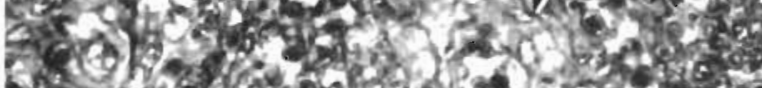

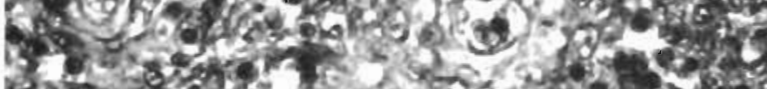
3. 20.

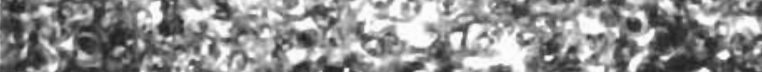

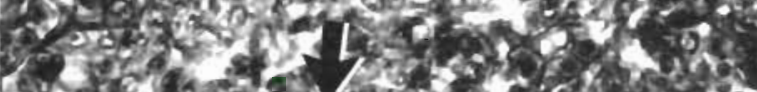

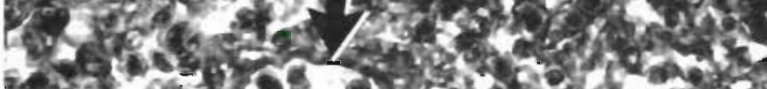
F.

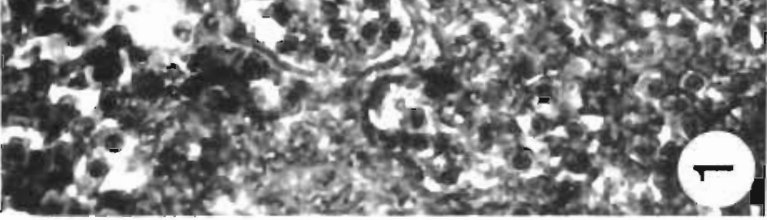

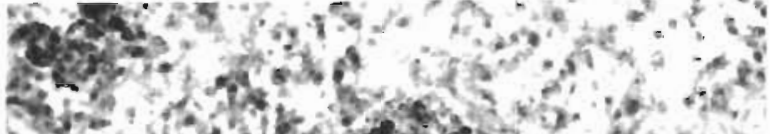

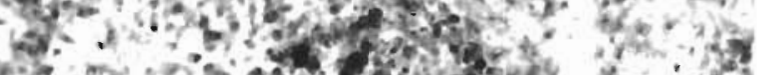

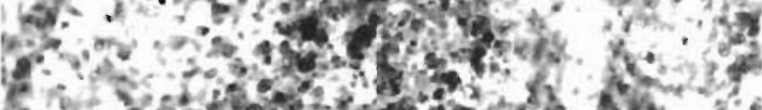

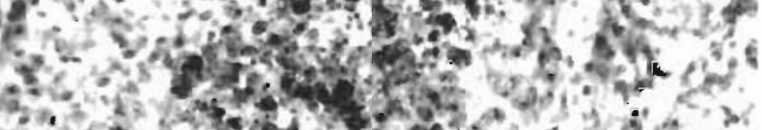

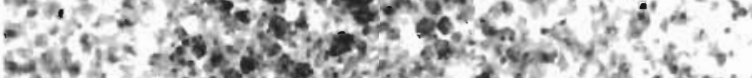

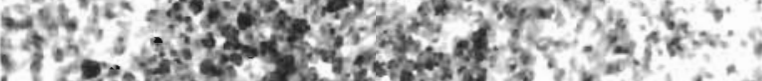

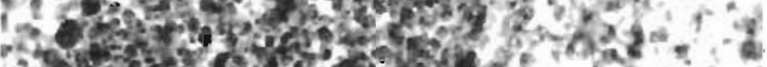

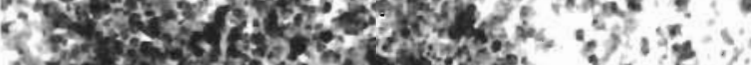

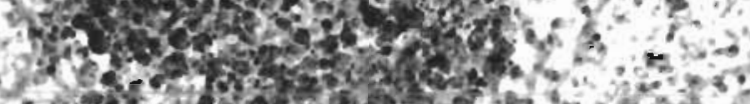

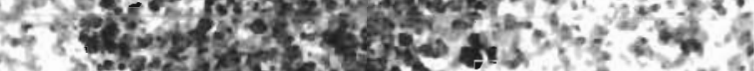
S.

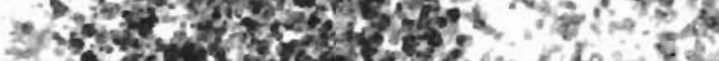

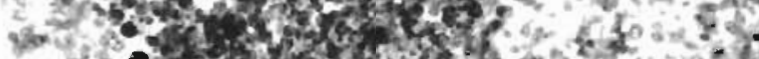
2.

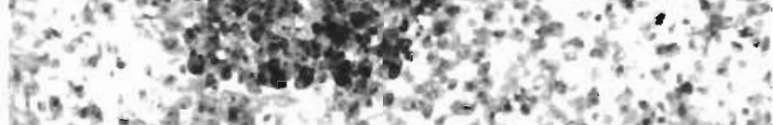

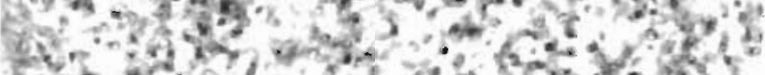

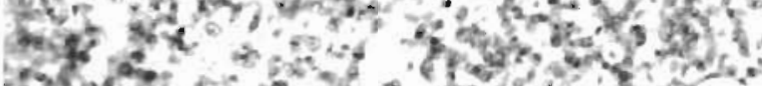

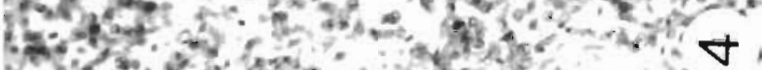

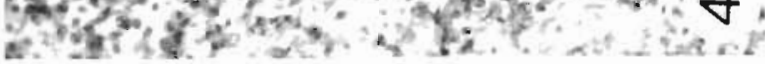

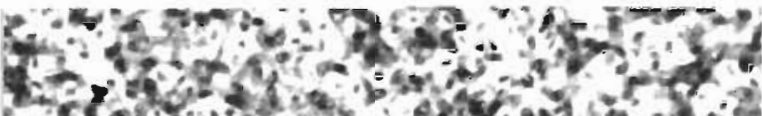

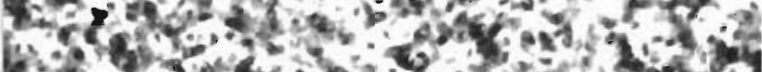

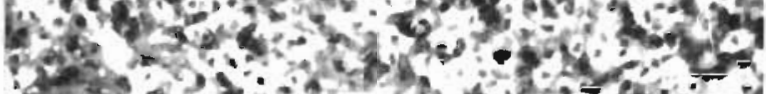

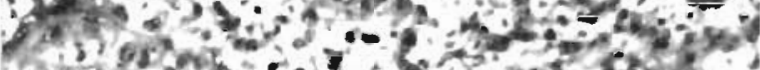

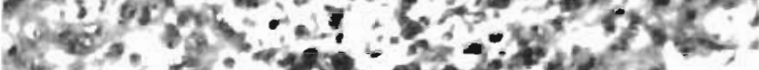

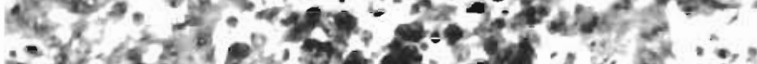

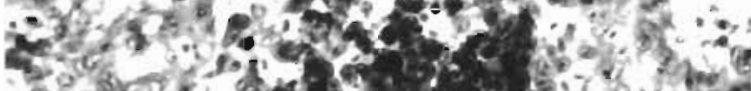

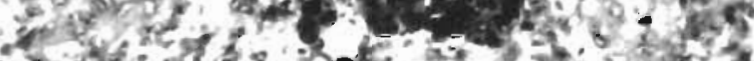

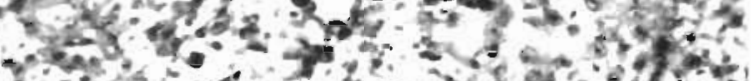

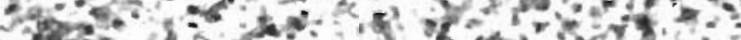

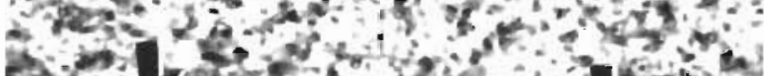

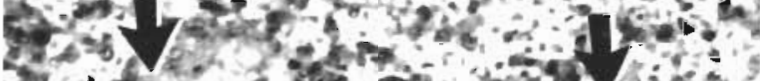

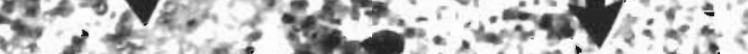
E. 20

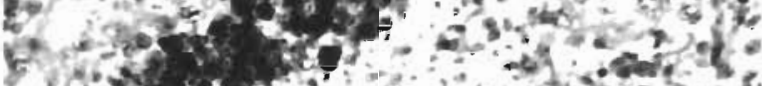

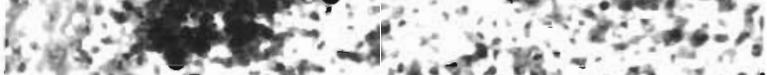

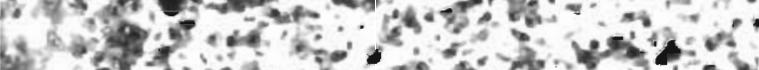

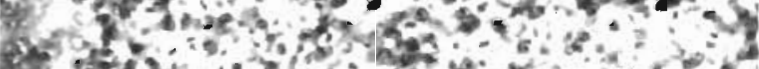

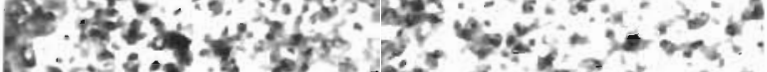

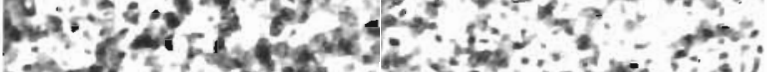

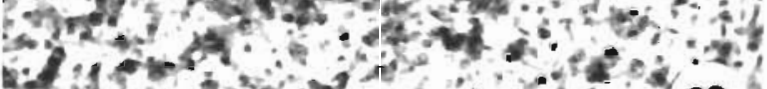

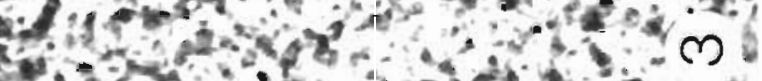



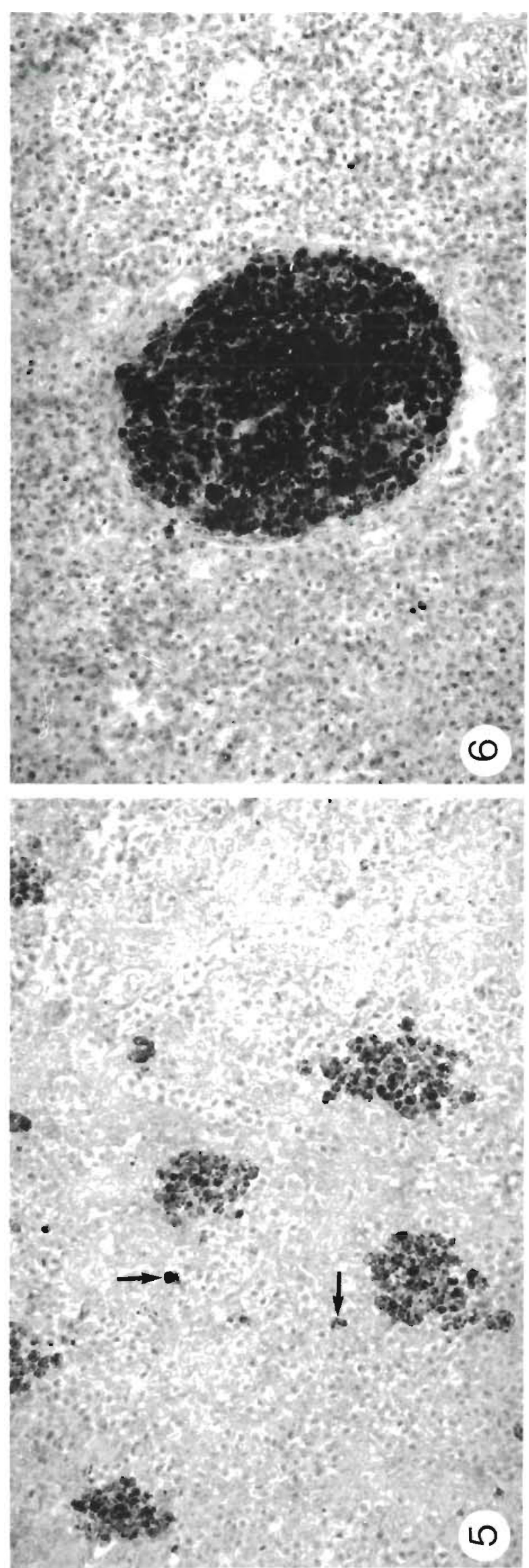

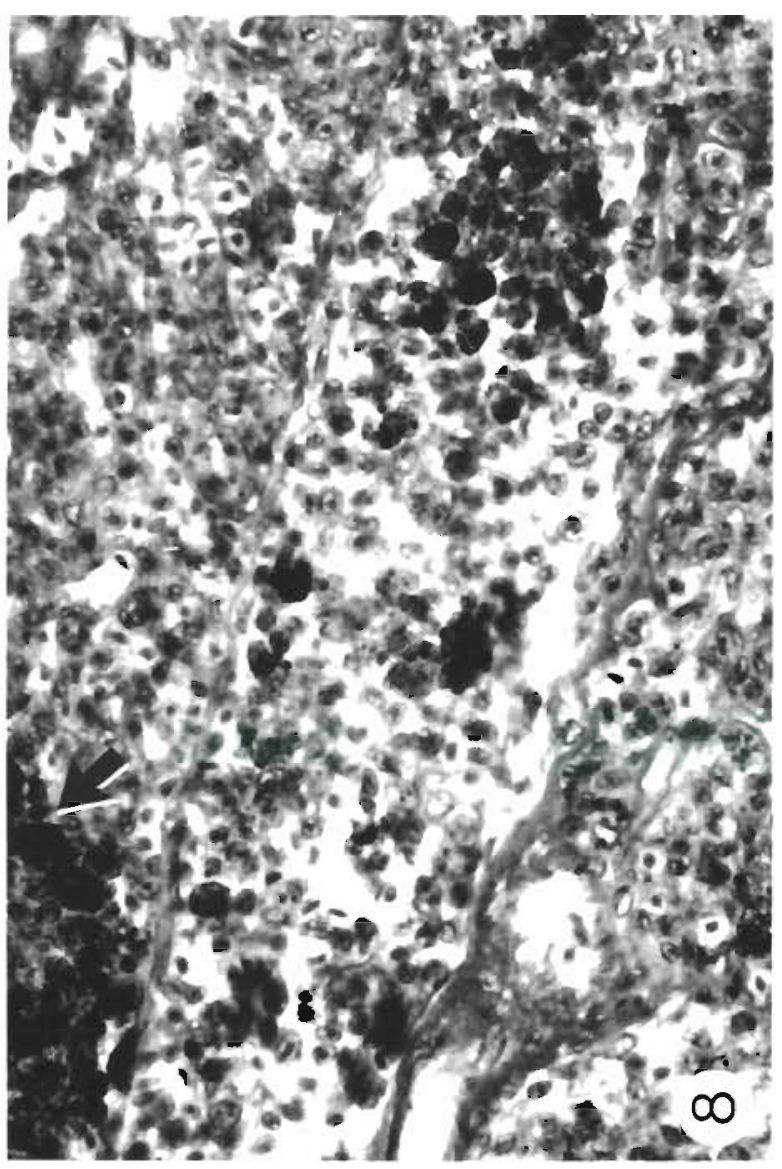

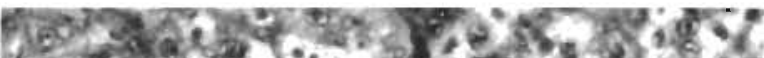

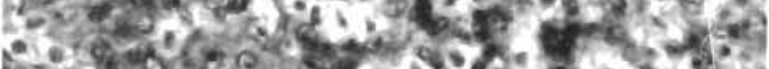

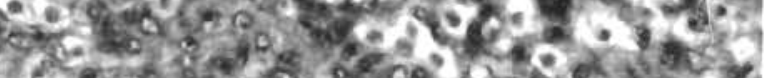

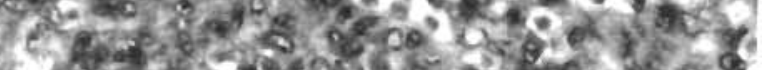

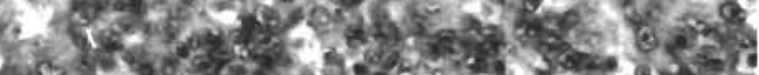

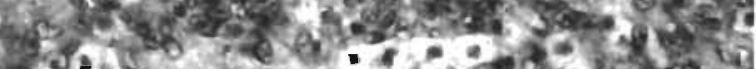

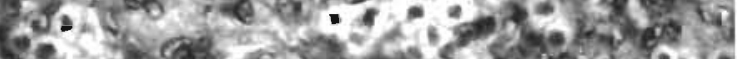

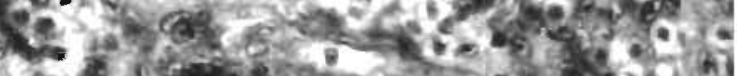

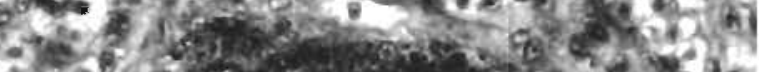

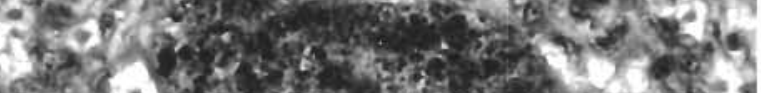

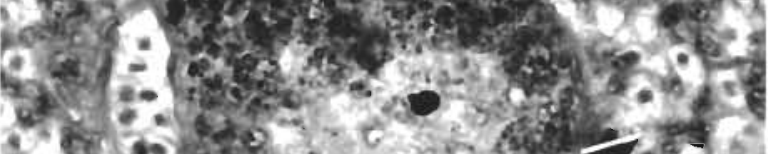

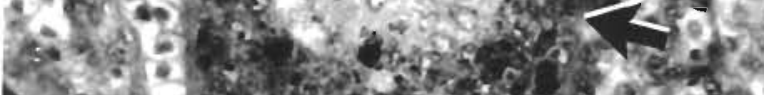

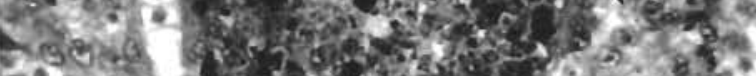

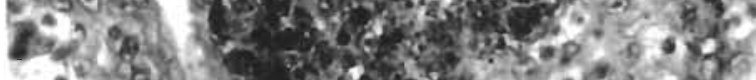

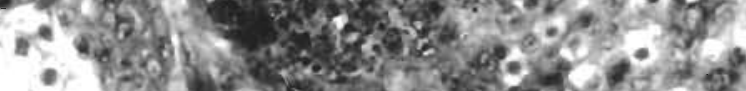

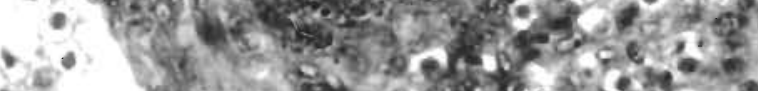

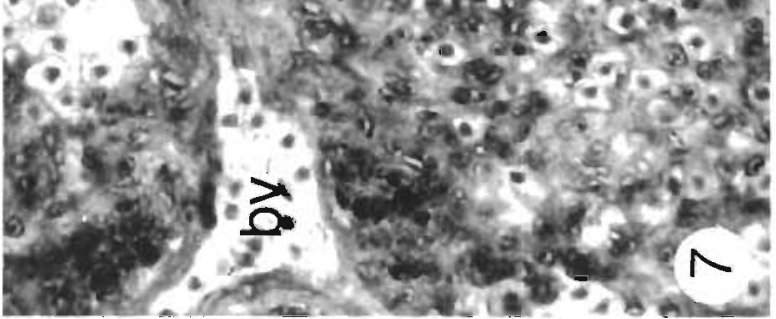

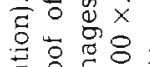

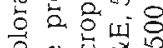

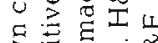

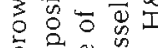

을

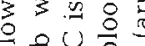

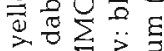

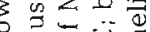

का

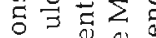

कิ

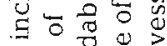

$\exists$

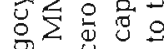

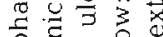

응

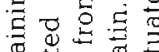

का $\sum_{0} \sum_{0}$

월

它

热问

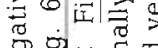

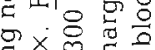

응

i 0 in

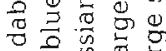

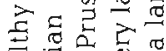

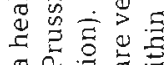

- $\pi 3$

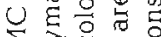

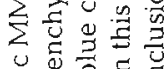

다의

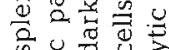

픙 3

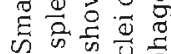

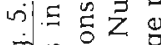

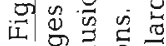

宁 $\frac{7}{2}$.

ฮี

ज

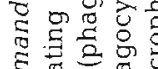

ง

$\infty$ है

क

它条要 
the head kidney (Brown \& George 1985) and in the spleen (Blazer et al. 1987) increase in frequency with fish age. Although dab between 19 and $26 \mathrm{~cm}$ in length represented several length classes (Lozan in press), an influence of age differences on the results of the present investigation can be excluded. Every group of fish - healthy, ulcerous, and scarred - was composed of a similar mixture of diverse length classes with medium lengths which were not significantly different.

Statements in the literature about alterations of MMC under conditions of infection are not completely consistent. Huizinga et al. (1979) reported that MMC in spleen, liver, and head kidney increased in frequency in bass Micropterus salmoides with red-sore disease. Concerning the reaction of MMC, it seems to be important which stage of the disease is described. Aquarium experiments with infected flat-fish have allowed differentiation of three stages in ulcer disease on the basis of the clinical appearance and of the histopathological changes; MMC have been mentioned in some reports (Home et al. 1977, Richards 1980). Apart from a darkening in skin coloration, there is practically no externally visible alteration in the peracute stage. The spleen exhibits a decomposition of red and white pulp, and $\mathrm{MMC}$ either disappear or undergo destructive processes, according to the age of the fish. The subsequent acute phase is characterized by the beginning of lesions with oedematous, non-bloody discolorations on the body surface. Only the chronic stage is marked by bloody ulcers extending deep into the musculature. In both of these later stages there is enhanced accumulation of haemosiderin-iron in splenic MMC, and not until the chronic stage is a haematopoietic proliferation initiated in the spleen.

In dab, the increase in haemosiderin accumulation during the chronic stage has been confirmed. Haemosiderin is derived from catabolism of haemoglobin from effete erythrocytes and is an intermediate metabolic product that occurs during recycling of components for erythropoiesis. There are 2 possible mechanisms by which the augmented haemosideriniron content may have come about: (1) the increased catabolism of damaged erythrocytes caused, for example, by lytic toxins from infectious agents; and (2) the increased retention of iron within MMC as a protective mechanism. It is known that in mammals a reduction of the iron content in blood serum results in a bacteriostatic effect (Bullen 1981).

The second important observation recorded in the present investigation, which is connected with the increase in size of splenic $M M C$, is the increased occurrence of cells lacking pigment deposits. These cells were either interspersed among the aggregated pigmented macrophages or concentrated in the centre of the MMC. Because an unequivocal identification of this cell type is impossible using light microscopy it can only be speculated that they represented immuno-competent cells with functions other than phagocytosis. Lamers (1986) reported that parallel to the macrophage-associated transport of injected antigen (which followed the same route as injected carbon particles) pyroninophilic cells appeared in the splenic parenchyma and in the MMC. These cells were plasma cells or precursor cells of haemo-, lympho- or granulopoiesis. If these pyroninophilic cells are identical to the cells predominantly occurring in the MMC of $\mathrm{dab}$ with ulcers this would indicate that an important additional function of MMC during this last, chronic, stage of infection is the production of immuno-competent cells in a manner analogous to that of the germinal centres of lymph nodes in mammals.

During enhancement of phagocytic activity, the spleen of fish is characterized by an augmented migration of macrophages within the parenchyma between ellipsoids and MMC (Ferguson 1976). Destruction of MMC is accompanied by the occurrence of pigmented macrophages within blood vessels which possibly derive from fragmentation of the MMC (Kranz \& Gercken 1987). In both cases MMC have lost their regular rounded surface structure. In the splenic parenchyma and blood vessels of ulcerous dab, the frequency of macrophages was reduced. In parallel, the surface of the MMC exhibited a regular shape. These observations can be interpreted as the result of at least a non-elevated turnover of phagocytic cells in the formation and destruction of MMC. Possibly such augmented activity might have happened mainly during an earlier stage of disease.

The results of the present investigation with dab clearly show that all changes in splenic parameters that have occurred during ulcerous infection are attenuated after healing of the wounds. However, the levels found in healthy fish are not totally regained as long as scars are visible. This interval between healing of ulcers and disappearance of visible scars extends over about 1 yr (B. Watermann pers. comm.). Up to now, the literature has not included any explicit statement on the extent to which alterations in MMC decline after interruption of the noxae. The only investigations dealing with the fate of $\mathrm{MMC}$ after their stimulation are from Herraez \& Zapata (1986) who describe a fragmentation of MMC following an immense enlargement induced by intoxication of the fish with phenylhydrazine, and from Lamers \& De Haas (1985) who discovered that injected antibodies were still demonstrable 12 mo after injection. Perhaps this time corresponds to the period, needed by the MMC and associated parenchymal structures in the spleen of dab for reorganization after ulcer disease has been overcome.

The investigation has shown that during the chronic 
phase of ulcer disease the size of splenic MMC is increased even though the main process of enlargement may occur earlier. The MMC changes in ulcerous fish tend to disappear with the removal of the noxae, although this process may be a long and drawn out one.

\section{LITERATURE CITED}

Agius, C. (1979). The role of melano-macrophage centres in iron storage in normal and diseased fish. J. Fish Dis. 2 $337-343$

Agius, C., Agbede, S. A. (1984). An electron microscopical study on the genesis of lipofuscin, melanin and haemosiderin in the haemopoietic tissue of fish. J. Fish Biol. 24: 471-488

Agius, C. Roberts, R. J. (1981). Effects of starvation on the melano-macrophage centres of fish. J. Fish Biol. 19. $161-169$

Blazer, V S., Wolke, R. E., Brown, J., Powell, C. A. (1987). Piscine macrophage aggregate parameters as health monitors: effect of age, sex, relative weight, season and site quality in largemouth bass (Micropterus salmoides). Aquat. Toxic. 10 (4): 199-215

Brown, C. L., George, C. J. (1985). Age dependent accumulation of macrophage aggregates in the yellow perch, Perca fluviatilis (Mitchell). J. Fish Dis. 8: 135-138

Bullen, J. J. (1981). The significance of iron in infection. Rev Infect. Dis. 3 (6): 1127-1138

Dethlefsen, V (1984). Diseases of North Sea fishes. Helgoländer Meeresunters. 37: 353-374

Edelstein, L. M. (1971). Melanin: a unique biopolymer In Ioachim, H. L. (ed.) Pathobiology annual. Butterworth, London, p. 309-324

Ellis, A. E. (1980). Antigen-trapping in the spleen and kidney of the plaice Pleuronectes platessa L. J. Fish Dis. 3: $413-426$

Ferguson, H. W. (1976). The relationship between ellipsoids and melano-macrophage centres in the spleen of turbot (Scophthalmus maximus). J. comp. Path. 86: $377-380$

Herraez, M. P., Zapata, A. G. (1986). Structure and function of the melano-macrophage centres of the goldfish (Carassius auratus). Vet. Immun. Immunopath. 12: 117-126

Horne, M. T., Richards, R. H., Roberts, R. J., Smith, P. C (1977). Peracute vibriosis in juvenile turbot Scophthalmus maximus. J. Fish Biol. 11. 355-361

Huizinga, H. W., Esch, G. W., Hazen, T C. (1979). Histopathology of red-sore disease (Aeromonas hydrophila) in naturally and experimentally infected largemouth bass Micropterus salmoides (Lacepede). J. Fish Dis. 2: 263-277

Jensen, N. J., Larsen, J. L. (1982). The ulcus syndrome in cod Gadus morhua. 4. Transmission experiments with 2 viruses isolated from cod and Vibrio anguillarum. Nord. Vet. Med 34: $136-142$

Kranz, H., Gercken, J. (1987). Effects of sublethal concentrations of potassium dichromate on the occurrence of splenic melano-macrophage centres in ju:enile plaice Pleuronectes platessa, L. J. Fish Biol. 31 (Suppl. A): 75-80

Kranz, H., Peters, N. (1984). Melano-macrophage centres in liver and spleen of ruffe (Gymnocephalus cernua) from the Elbe Estuary. Helgoländer Meeresunters. 37: 415-424

Lamers, C. H. J. (1986). Histophysiology of a primary immune response against Aeromonas hydrophila in carp (Cyprinus carpio L.). J. exp. Zool. 238: 71-80

Lamers, C. H. J. De Haas, M. J. H. (1985). Antigen localization in the lymphoid organs of carp (Cyprinus carpio). Cell Tissue Res. 242: 491-498

Lamers, C. H. J., Parmentier, H. K. (1985). The fate of intraperitoneally injected carbon particles in cyprinid fish. Cell Tissue Res. 242: 499-503

Lozan, J. L. (in press). Investigation on the growth of the Dab (Limanda limanda, L.) in eight regions of the North Sea and comparisons with earlier findings. Arch. FischWiss.

Richards, R. H. (1980). Observations on vibriosis in cultured flatfish. In: Ahne, $W$ (ed.) Fish diseases. Third COPRAQSession. Springer, Berlin, p. 75-81

Roberts, R. J. (1978). Fish pathology. Baillière Tindall, London

Weeks, B. A., Warinner, J. E. (1984). Effects of toxic chemicals on macrophage phagocytosis in two estuarine fishes. Mar envir Res. 14: 327-335

Wolke, R. E., Murchelano, R. E., Dickstein, C. D., George, C. J. (1985). Preliminary evaluation of the use of macrophage aggregates (MA) as fish health monitors. Bull. envir. Contam. Toxic. 35: 222-227 